\title{
EL EDITOR MELLADO Y EL LICEO ARTÍSTICO LITERARIO
}

\author{
RaQuel PÉrez VAlle \\ UNED \\ raperval@gmail.com
}

\section{RESUMEN}

El famoso editor Francisco de Paula Mellado aparece vinculado a los círculos más progresistas del Madrid de las décadas de 1830 y 1840. La Milicia Nacional, las publicaciones punteras como El Español, El Iris o el Museo de las Familias, y la formación y desarrollo del Liceo Artístico y Literario no se pueden entender sin la imprescindible figura del editor granadino.

Palabras Clave: Mellado; Liceo Artístico y Literario; Milicia Nacional; cristinos; periodismo

\section{RÉSUMÉ}

Le célèbre éditeur Francisco de Paula Mellado est lié aux milieux les plus progressistes de Madrid des années 1830 et 1840. La Milice Nationale, les publications de premier plan telles que El Español, El Iris ou le Museo de las Familias, et aussi la formation et le développement du Liceo Artístico y Literario, ne peuvent pas être compris sans la figure essentielle de l'éditeur de Granada.

Mots-CLÉ: Mellado; Liceo Artístico y Literario; Milice Nationale; “cristinos”; journalisme

En el Madrid isabelino diferentes asociaciones culturales acogían en sus veladas recitales literarios variopintos y desiguales en cuanto a calidad. Entre ellas destacamos el Liceo Artístico Literario de Madrid (1837-1851) por su personal vinculación con el editor y director del Museo de las Familias, la revista ilustrada más longeva del periodo, Francisco de Paula Me- 
llado. Desde sus impulsivos inicios hasta finales de la década de los cuarenta, como iremos desgranando en este texto, el Liceo para el editor supuso una visita de obligado cumplimiento y su incondicional apoyo aunaba la defensa de sus principios morales, políticos y culturales con el hecho de conseguir en sus reuniones valiosísimos puntales en su fulgurante carrera editorial.

Del núcleo más activo del Parnasillo surgieron tanto el Ateneo como el Liceo. Este último fue fundado en su propia casa por José Fernández de la Vega ${ }^{1}$.

En él se asistía tanto a sesiones literarias o musicales como a exposiciones, talleres, conferencias o espectáculos teatrales. Estas actividades ${ }^{2}$ se recogían en la revista de la institución y también en casi todos los diarios y semanarios de la época, convirtiéndose en el trampolín perfecto para los artistas consolidados y los noveles: ser admitido entre los primeros ingenios significaba el acceso a la prensa, facilidades para publicar, ganarse un sustento como escritor y formar parte de un privilegiado y selecto círculo social.

Pero vamos a repasar los primeros años de la asociación y sus actividades para analizar los nexos de unión entre la misma y el editor Mellado desde sus orígenes.

José Fernández de la Vega y Potau (1803-1851), quien, como hemos mencionado, junto con un grupo de amigos cercanos había iniciado estas reuniones en su casa, vinculó la sociedad desde su génesis a la defensa de la reina regente M. ${ }^{a}$ Cristina; de hecho, varios investigadores apuntan a la filiación política de la misma ${ }^{3}$.

El inconveniente contexto de la primera guerra carlista (1833-1840) no propiciaba la imparcialidad de los ciudadanos. En un periodo de transición política y social se jugaban las primeras partidas entre los incipientes poderes fácticos culturales: el Liceo se vio en la disyuntiva de sucumbir ante el mecenazgo interesado o mantener, lo que por principios básicos mira de frente a la utopía, un nivel artístico elevado, continuo, multidisciplinar e independiente.

La relación de Fernández Vega, fundador del Liceo, con Mellado parece haber sido muy estrecha y acude a él como testigo cuando solicita la concesión de la Orden de Carlos III:

[...] Para ello necesitaba de testigos que probaran su honradez de costumbres y que afirmaran conocerle suficientemente indicando también su oficio y tiempo de residencia en Madrid, con esta finalidad contó con el testimonio de amigos y compañeros del Liceo: Juan Pérez Villamil, Leopoldo López de Gonzalo (ambos profesores de pintura en la villa de Madrid), Francisco de Paula Mellado (literato), Miguel Mellado (impresor), Pedro López (oficial retirado de las milicias provinciales) y Antonio Bernal (propietario) $[\ldots] .^{4}$

${ }^{1}$ Las reuniones también se celebraban en casa de Mariano de las Mercedes Roca de Togores y Carrasco (18121889), primer marqués de Molins y vizconde de Rocamora, orador, escritor y político conservador español.

2 Entre otras actividades culturales realizaron exposiciones anuales de Bellas Artes, origen de las Exposiciones Nacionales de Bellas Artes (la primera en 1856) y bailes de máscaras con gran fama, heredada por el Círculo de Bellas Artes.

3 Pérez de Guzmán, Juan (8-10-1900): "El Liceo Artístico y Literario. Las lecturas de Larra y Campoamor", La Ilustración Española y Americana, Madrid. Se mencionan interesadas implicaciones de los sectores intelectuales más conservadores capitaneados por Martínez de la Rosa.

${ }^{4}$ Pérez Sánchez, Aránzazu (2005): El Liceo Artístico y Literario de Madrid (1837-1851), Madrid, FUE, p. 43. 
El periodo de inicio y consolidación de la asociación, en el que el abogado catalán consta como Fundador-Presidente y Conservador, muy activo culturalmente, supone un cambio de ubicación del Liceo, siempre dentro de la misma zona geográfica ${ }^{5}$.

El éxito de público y asociados propiciaron las diferentes ubicaciones, cuatro en apenas medio año, buscando siempre locales más amplios donde albergar las intensas actividades de los socios, escogidos no por su clase social sino por sus aptitudes artísticas:

Tabla 1. Distintas ubicaciones del Liceo Artístico y Literario

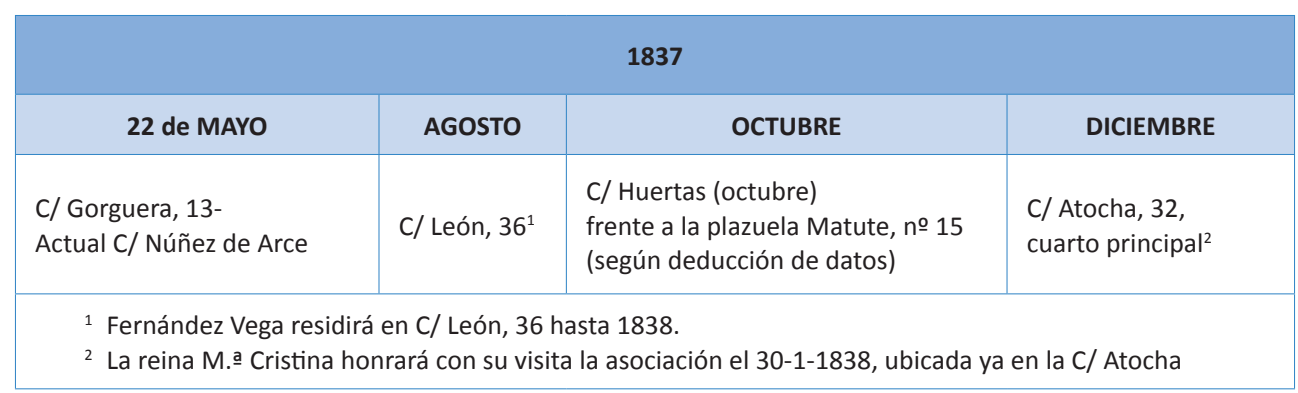

Francisco de Paula Mellado, quien comenzaba a dar sus primeros pasos en el mundo editorial, sitúa sus locales laborales, tanto el establecimiento tipográfico como el gabinete de lectura, en estos años, en la misma zona, llegando a coincidir también cronológicamente su ubicación en la C/ del Sordo con el cambio de localización del Liceo hacia la zona de la Carrera de San Jerónimo. El editor granadino siempre buscaba la proximidad con la asociación:

Tabla 2. Diferentes ubicaciones de los locales laborales de Francisco de Paula Mellado

\section{DIFERENTES UBICACIONES DEL ESTABLECIMIENTO TIPOGRÁFICO Y DEL GABINETE DE LECTURA}

\begin{tabular}{|c|c|c|c|c|}
\hline $\begin{array}{l}1836-37 \\
\text { (imprenta de la } \\
\text { Estafeta) }\end{array}$ & 1838 & $1838-43$ & $1844-1863$ & $\begin{array}{l}\text { A partir del 30-9-1837 } \\
\text { GABINETE DE LECTURA } 3\end{array}$ \\
\hline $\begin{array}{l}\text { C/ Santa María y } \\
\text { C/ León, 18, 40 Pcpal }\end{array}$ & C/ Huertas, 61 & $\begin{array}{l}\text { C/ del Sordo, } 11 \\
\text { Actual C/ Zorrilla }\end{array}$ & $\begin{array}{l}\text { C/ Santa Teresa, } 8^{4} \\
\text { Actual C/ Campoamor }\end{array}$ & C/ Del Príncipe, 25 \\
\hline \multicolumn{5}{|c|}{$\begin{array}{l}{ }^{3} \text { Los primeros datos concretos que hemos encontrado sobre el gabinete de lectura del editor granadino se } \\
\text { incluyen en el periódico La Estafeta (30-9-1837) publicado por el propio Mellado. } \\
{ }^{4} \text { Cuando aún seguía existiendo su vínculo con el Liceo, se establece definitivamente en C/ Santa Teresa, } 8 \\
\text { (1844-1863), ampliando posteriormente la editorial (C/ Costanilla de Santa Teresa, 3). }\end{array}$} \\
\hline
\end{tabular}

${ }^{5}$ Se instalarán definitivamente (3-1-1839) en el Palacio de los duques de Villahemosa, carrera de San Jerónimo esquina P. ${ }^{\circ}$ del Prado, actualmente Museo Thyssen Bornemisza, más alejados de su ubicación originaria en la que compartían ambiente con los círculos más bohemios y culturales de la capital. 
Un breve repaso de la biografía de Mellado (1807-1876) ${ }^{6}$ nos ayudará a entender mejor este empeño por consolidar sus pasos en el Liceo Artístico y Literario Español.

Su familia y él se trasladan desde su ciudad natal, Granada, a Madrid en una fecha por ahora desconocida. Mientras que apenas se dispone de alguna referencia de su hermano, contamos con interesantes datos sobre sus hermanas, ambas casadas con amigos del círculo más próximo al editor: Carmen con Luis Rey (destacado miembro del Liceo, concretamente de la Sección de Declamación; socio n. $\left.{ }^{0} 855\right)^{7}$ y M. ${ }^{a}$ Concepción (1818-1888) con el conocido periodista e historiador Fray Gerundio, Modesto Lafuente (socio no 398$)^{8}$.

Las primeras publicaciones de Mellado en la capital como escritor y traductor-adaptador datan de principios de la década de los 30, en el convulso final de reinado de Fernando VII: Recreo de Damas ó las noches en Paris (Madrid, Imp. de D. Pedro Sanz, 1831), La tertulia de invierno (Madrid, Imp. que fue de Fuentenebro, 1831), Clermont (Madrid, Imp. que fue de Fuentenebro, 1831), Días fúnebres (Madrid, Imp. que fue de Fuentenebro, 1832), Lo que son ellos (Madrid, Imp. de D. Miguel de Burgos ${ }^{9}, 1832$ ) y Arte de fumar y tomar tabaco sin disgustar a las damas (Madrid, Imp. De Repullés ${ }^{10}$, 1833).

Sin embargo su libro más vendido, todo un best seller para la época con más de 12 ediciones, fue Guía del viajero en España, publicado por primera vez en 1842, cuando Mellado desarrollaba paralelamente sus actividades como escritor, periodista y editor.

Su círculo de amistades en Madrid determinará su trayectoria vital y profesional, especialmente su vínculo con Bernardino Núñez de Arenas Blanco (1806-1865), su consejero, su asesor financiero ${ }^{11}$ y finalmente su consuegro.

El periodista y político conquense en su juventud había participado en la sociedad secreta "Los Numantinos" (1823-1825), con sus amigos, también como él discípulos de Alberto Lista, José de Espronceda (1808-1842), Ventura de la Vega (1807-1865) y Patricio de la Escosura (1807-1878). En 1834, en compañía de dos de ellos, Ventura de la Vega y Espronceda, y la de Antonio Ros de Olano (1808-1886) fundó el periódico El Siglo (órgano de la joven oposición liberal y romántica $)^{12}$ que también dirigirá. En él colaborarán otros personajes relevantes del círculo más próximo a Mellado como Nicomedes Pastor Díaz (1811-1863) o José García de Villalta (1801-1846).

${ }^{6}$ Agradecemos a doña Inmaculada Bertos Maldonado (Archivo Histórico Diocesano de Granada) su colaboración a la hora de corroborar las fechas de nacimiento de Francisco de Paula Mellado (27 de octubre de 1807) y de varios miembros de su familia.

7 En los mismos años, 1841-1842, constan también como socias Rosario y Vicenta Rey, quienes presumiblemente podrían tratarse de sus hermanas. También en esas fechas aparece el nombre de Carmen Mellado (socia n. ${ }^{\circ}$ 756).

${ }^{8}$ En los mismos años, 1841-1842, también constan Carmen, Irene y Pilar Lafuente, quienes, como en el caso de Luis María Rey, podrían ser familiares del escritor.

${ }_{9}$ Consta como socio del Liceo desde 1838.

${ }^{10}$ Vicente Repullés, socio n. ${ }^{\text {}} 739$ del Liceo.

11 Además de asesorarle, Núñez de Arenas le prestó dinero en varias ocasiones. Así, gracias a un préstamo suyo sin intereses, Mellado adquirió por 240.000 rs. en enero de 1846 el edificio que pasaría a ser la sede del Establecimiento Tipográfico, números 5 y 8 de C/ Costanilla de Sta Teresa.

${ }_{12}$ El Siglo, Madrid, Imp. de Marcelino Calero y Potocarrero, N.o 1 (21-1-1834)-Nº 14 (7-3-1834). Fue suprimido por Real Orden. 
El ocho de marzo de 1834 una comisión municipal abrió en Madrid el registro de alistamiento en la Milicia Urbana ${ }^{13}$. Entre los primeros voluntarios se presentaron los redactores de El Siglo: Bernardino Núñez de Arenas (socio n. ${ }^{\circ} 14$ del Liceo), José de Espronceda (socio n. $\left.{ }^{\circ} 17\right)$ y Ventura de la Vega (socio n. ${ }^{\circ} 18$ ). Otros de sus componentes eran: Antonio Esquivel (socio n. ${ }^{\circ}$ 195), Genaro Pérez Villamil (socio n. ${ }^{\circ}$ 182), Ramón Carnicer (socio en 1838), Juan Latorre (socio n. ${ }^{\circ} 402$ ), Julián Romea (socio n. ${ }^{\circ}$ 170), Larra (quien fallece pocos días antes de las primeras reuniones), García de Villalta (socio n. ${ }^{\circ}$ 136), Basilio Sebastián Castellanos (socio fundador y en los primeros años en la directiva), Jacinto Salas y Quiroga (socio n. ${ }^{\circ}$ 172), Ramón Mesonero Romanos (socio n. ${ }^{\circ}$ 164) o González Bravo (socio desde inicios).

Los fuertes vínculos de este grupo de intelectuales, como vemos por las fechas que incluimos de generaciones distintas pero con intereses comunes, evidencian la relación existente entre ellos en diferentes ámbitos: al igual que se implicaban de manera directa en la Milicia, también lo harían respondiendo al unísono a la hora de formar un frente cultural común contra el carlismo.

Núñez de Arenas perteneció al segundo batallón de la Milicia Nacional (1836) ${ }^{14}$ al igual que Andrés Borrego (1802-1891) ${ }^{15}$, José M. ${ }^{a}$ Carnerero (1784-1866), Alcalá Galiano o Istúriz, pasando pronto a ser elegido capitán de la compañía ${ }^{16}$. La lista de personajes relevantes que pertenecieron a dicha milicia voluntaria se encontraba nutrida con lo más granado de la época. A los antes mencionados añadimos los de Manuel Bretón de los Herreros (socio del Liceo n. ${ }^{\circ}$ 145), Francisco Fernández Villabrille, Pascual Madoz,... gran parte de ellos integrantes del grupo más próximo a Francisco de Paula Mellado y con los que, además, tuvo ocasión de colaborar en sus diferentes publicaciones.

La Milicia Nacional (1833-1843), grupo heterogéneo ideológica, social y generacionalmente, implicó al ciudadano como constructor de un nuevo estado frente a los carlistas y sus aspiraciones absolutistas. Su apoyo en la Regencia a Espartero, conllevó la contrariedad de los moderados y, con toda probabilidad, su fulminante desaparición a finales de 1843 y principios $1844 .{ }^{17}$

En la época de su formación, Mellado ya colaboraba como periodista en el diario de la tarde $E l$ Tiempo ${ }^{18}$, periódico cercano al gobierno de la reina madre $\mathrm{M}^{\mathrm{a}}$ Cristina. La que había

${ }_{13}$ Precisamente fue el capitán de la Milicia Nacional, Juan Miguel de los Ríos, quien consiguió dar una nueva vida a otra de las asociaciones culturales más importantes de la época, el Ateneo.

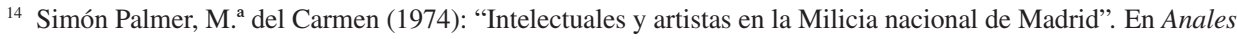
del Instituto de Estudios Madrileños, X, pp. 319-40.

15 Recordamos que crea la Compañía Tipográfica, con una especial aportación económica entre otros, de Gaspar Remisa, cuya imprenta publica la revista del Liceo Artístico y Literario y El Español.

${ }^{16}$ Como indica M. a del Carmen Simón Palmer en el citado estudio, la mala gestión tanto de la Milicia como de Núñez de Arenas le llevan a este último a abandonarla como posteriormente haría Bretón de los Herreros, expulsado tras el estreno de su obra teatral La Ponchada (1840).

${ }_{17}$ Seguimos la información de Pérez Garzón, Juan Sisinio (1978): Milicia nacional y revolución burguesa: el prototipo madrileño, 1808-1874, Madrid, CSIC Press.

${ }^{18}$ El Tiempo. Periódico de la tarde, Madrid, Impr. de Verges, n. ${ }^{\circ} 1$ (2-12-1833) n. ${ }^{\circ} 169$ (19-5-1834). Después se imprimirá en la de F. Pascual o la de Tomas Jordán. Mellado se presentó ante el Tribunal de imprentas y librerías del Reino como representante de la redacción solicitando un cambio de título del periódico y el uso de temas políticos 
sido una publicación artística, científica y literaria ("Semanario Crítico") que recogía las principales noticias de los periódicos españoles, ingleses y franceses (método que continuará desarrollando Mellado en la gran mayoría de sus publicaciones periódicas) a partir del $\mathrm{n}$. $^{\circ}$ 143 se subtituló "Periódico dirigido a la Milicia Urbana"19, ocupando sus novedades un puesto privilegiado en las noticias del mismo.

A pesar de tratarse de un periódico afín al gobierno, la férrea censura de la época provocó el cierre directo de El Tiempo tras una Orden de la Reina Gobernadora (finales de mayo de 1834).

Antonio Ferrer del Río, también gran amigo de Mellado, menciona su participación como taquígrafo en otro de los periódicos más destacados del momento, El Español (1-11-1835/3112-1837): "Bajó la dirección de Martí también figuraron como taquígrafos de El Español, entre los aún vivos, D. Eugenio Moreno López, D. Antonio María Segovia, D. Francisco de Paula Mellado, nombres todos bien conocidos desde entonces"20.

Hasta finales de 1836 no disponemos de datos en firme de una nueva publicación, además de El Español, en la que participe Francisco de Paula Mellado pero sí nos consta que hubo de haber más ya que a mediados de 1834, poco después del cierre de El Tiempo, en el Diario de Avisos, Mellado, junto a varios periodistas más, figura como una de las personas que solicita permiso para publicar periódicos:

[...] Don Antonio Gutiérrez, D. Francisco de Paula Mellado, D. Jerónimo Ferrer y Vals [...] se servirán pasar a la secretaría del gobierno civil de esta provincia a enterarse de una real orden relativa a las instancias que respectivamente han hecho en solicitud de real permiso para publicaciones de periódicos. Madrid, 4 de junio de 1834 [...]. ${ }^{21}$

En el ámbito personal destacamos su enlace matrimonial (2-9-1835) con la madrileña Isidra M. ${ }^{a}$ Leguey (socia n. ${ }^{\circ} 491$ del Liceo), hija de D. Pedro Leguey y doña Antonia Monsó. Mellado inicia su carrera como editor un año después de casarse, con el primer periódico exclusivamente de noticias, La Estafeta (1836), que finalmente será absorbido por el Nosotros, de corte más satírico; en él publicaban reputados periodistas como Abenámar (Santos López Pelegrín; socio en el Liceo desde 1838) y el Estudiante (Antonio M. ${ }^{a}$ Segovia; socio n. ${ }^{\circ} 171$ ), compañero suyo de El Español. Sus ideas afines les llevarán a que acompañen a Mellado en la consolidación del Liceo y en sus primeros proyectos editoriales.

Pocos meses antes de que viese la luz la revista señera de su establecimiento tipográfico, el Museo de las Familias, nació Fernando, el único hijo que hasta ahora le conocemos. Los

en sus páginas. Seguimos a López Zazo, Ruth (2010): La actividad editorial de Francisco de Paula Mellado, Trabajo de investigación, Madrid, UCM.

${ }^{19}$ Un Estatuto Real (1834) la había denominado "Milicia Urbana" pero después del motín de la Granja de San Ildefonso (1836), la de nuevo "Milicia Nacional" se reorganizó con unas bases similares a las del Trienio. Esta institución posiblemente constituyó un nexo de unión más entre el editor granadino y este círculo político y cultural de la capital. No sería de extrañar, a la luz de los datos aportados, que el propio Mellado también se incluyese entre sus filas.

${ }^{20}$ Ferrer del Río, Antonio (1868): “Don Julián Romea y su época en el teatro”, Revista de España, Madrid, Tomo III, p. 617.

${ }^{21}$ Diario de Avisos, Madrid, 6-6-1835, n. ${ }^{\circ} 157$, p. 665. 
padrinos de Fernando Mellado Leguey (25-10-1842/15-1-1912) fueron los íntimos amigos del editor, el mencionado Bernardino Núñez de Arenas y su esposa Fernanda Bravo Piqueras, llevando como nombre el de su madrina. El matrimonio amigo de los Mellado tuvo cuatro hijos, y la más pequeña, Matilde, se casará ${ }^{22}$ con Fernando, uniendo más si cabe a las dos familias.

Tras este breve repaso biográfico sobre el editor Mellado, en el que hemos comprobado su vinculación con los miembros de la Milicia Nacional, con el círculo de defensores de la reina regente M. ${ }^{\text {a }}$ Cristina y con los socios fundadores del Liceo, continuaremos con la descripción de la asociación.

En la primera etapa del Liceo se configuraron sus estatutos y se fijaron las características del establecimiento. Como señala el profesor Robert Marrast:

[...] El Liceo se atribuyó unos estatutos, en los cuales la sociedad aparece definida como "dedicada exclusivamente a procurar el fomento y prosperidad de la literatura y de las bellas artes". Se compone de seis secciones -de literatura, pintura, escultura, arquitectura, música y miembros simpatizantes- dirigida cada una de ellas por una junta, presidida por el fundador y conservador Fernández de la Vega asistido por dos vicepresidentes. Cada socio (excepto los simpatizantes) se compromete a dar cada mes al Liceo una composición en verso o en prosa, una litografía o un fragmento de música original $[\ldots]^{23}$

En la tertulia literaria de los jueves, en las sesiones de competencia, escritores conocidos alternaban con los principiantes, leyendo y recitando prosa o verso. Así las describe el celebrado autor de Don Juan Tenorio:

(En referencia a José García de Villalta, quien le ofrece trabajar en El Español, y a los poemas que publicaba en este diario): [...] Es verdad que contribuía a darlos boga las lecturas que de ellos hacía en los salones del LICEO, en el palacio de los duques de Villahermosa, quienes, ausentes de Madrid a la sazón, se los habían cedido a aquella sociedad literaria y artística. Era el Liceo... [...] Allí, en el Liceo, reñí yo y gané grandes batallas, y cobré fama de gran lector; allí ayudé a subir a la tribuna y entrar a la palestra literaria a Rodríguez Rubí, con su precioso romance "La venta del jaco"; allí coroné una noche a Carolina Coronado y presenté una mañana a Gertrudis Gómez de Avellaneda; allí... pero lo que sucedió allí lo sabe todo el mundo y lo que no sepa se lo dirá mejor que yo el Curioso Parlante (Paréntesis mío). ${ }^{24}$

Entre la larga lista de sus asistentes habituales apuntamos a: Pastor Díaz, Romero Larrañaga, González Bravo, Escosura, Espronceda, Enrique Gil, Ventura de la Vega, Alcalá Galiano, García de Villalta, Gil y Zárate, Bretón de los Herreros, Gorostiza, Julián Romea, Martínez de la Rosa, Donoso Cortés, el Duque de Rivas, el conde de Toreno, Quintana, los

${ }^{22}$ El matrimonio de Matilde Núñez de Arenas y Fernando Mellado tuvo tres hijos: Carmen, Fernando e Isidro, a los que se unió una sobrina de Matilde que se quedó huérfana (Fernanda Núñez-Arenas y Méndez de Vigo). Carmen Mellado, nieta del editor granadino, y Rafael Gutiérrez, su esposo, van a ser los padres de uno de los personajes más relevantes en la transición política española de la dictadura a la democracia, Manuel Gutiérrez Mellado.

${ }_{23}$ Marrast, Robert (1989): José de Espronceda y su tiempo, Madrid, Crítica, pp. 571-572.

${ }^{24}$ Zorrilla, José (1880): Recuerdos del tiempo viejo, Impr. de los Sucesores de Ramírez, Barcelona, pp. 44 y 45. 
Madrazo, Ochoa, García Gutiérrez, Carlos Latorre, Mesonero Romanos ${ }^{25}$, Salas y Quiroga, Navarrete, Mellado, Estébanez Calderón, Miguel de los Santos Álvarez, Antonio M. a Segovia, José de la Revilla,... sin contar a la reina madre y a la propia Isabel II.

Al poco tiempo, sus reuniones se convirtieron en visita obligada para aquellos que querían estar a la moda en la capital, albergando en sus salones a aristócratas, diplomáticos, políticos, cortesanos... quienes paulatinamente dispondrán de más importancia y desplazarán tanto los intereses como las intenciones originarias de la asociación hacia ámbitos menos ligados a la exclusiva creación, divulgación y aprendizaje artístico y cultural.

Como también testifica Enrique Gil en el Correo Nacional, cobran especial relevancia las diferentes representaciones en Teatro en el Liceo: Ópera, el 20-3-1839 (Bárbara Lamadrid, discípula del compositor Basilio Basili) o la "Representación de García del Castañar" (7-8-1839).

El propio Gil y Carrasco, en dos artículos sucesivos de este periódico, detalla pormenorizadamente las diferentes cátedras (3-4-1839) y alababa, además de las sesiones culturales, la impartición de docencia (12-4-1839) 26 :

[...] Las sesiones ordinarias y extraordinarias de competencia nos han sabido presentar a un mismo tiempo los encantos de las poesías, las armonías de la música y las magias del pincel, junto con el atractivo de una brillante y acogida sociedad. Mucho tiempo se pasará antes de que se olvide la introducción al poema del Diablo Mundo del señor Espronceda, los robustos adentros del señor Salas o los delicados y riquísimos de las señoras de Vega y Bonapla, y los espléndidos cuadros de Villamil o los maravillosos dibujos de la señorita Weis [...].

El Liceo hasta el día no había cumplido la misión de enseñanza que le estaba encomendada, en el día la cumple; en el día dominó lo presente y señala el porvenir; [.. . La numerosa concurrencia que ha asistido a las lecciones, entre la cual se ha visto algunas señoras artistas, han justificado la elección que el Liceo ha hecho de sus profesores, jóvenes todos y desconocidos como maestros [...]. ${ }^{27}$

Las distintas actividades del Liceo disponían del impagable eco mediático de las publicaciones periódicas más influyentes del momento, contribuyendo indudablemente a incrementar exponencialmente su prestigio y el interés que despertaba entre la sociedad madrileña. Incluso Fernández Vega fundará la revista de la asociación, subtitulada "periódico mensual",

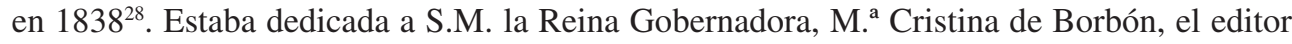
responsable era el mismo Fernández Vega y la imprimía la Compañía Tipográfica.

Fue Andrés Borrego quien constituyó la Compañía Tipográfica, primera empresa editorial de la prensa española con talleres propios. El capital de esta Sociedad Anónima lo apor-

${ }^{25}$ Muchos de estos relevantes personajes, como Mesonero, Ventura de la Vega, Bernardino y José Núñez de Arenas, previamente había organizado otro tipo de asociaciones como la Real Sociedad Madrileña de Amigos del País (1834-1835).

${ }^{26}$ Enrique Gil deja patente su descontento en dichos artículos porque se ha invertido el orden a la hora de publicarlos. El $1^{\circ}$ en publicarse debería haber sido el del 12 de abril, artículo que trataba sobre las actividades de la asociación.

${ }^{27}$ Gil y Carrasco, Enrique (12-3-1839): "Revista de cursos literarios y científicos", Correo Nacional, Madrid.

${ }_{28}$ Hartzenbusch, Eugenio (1993): Apuntes para un catálogo de periódicos madrileños desde el año 1661 al 1870, Madrid, Ollero \& Ramos. "Pr. en enero de 1838, repartiéndose mensualmente, en cuadernos de unas 48 páginas de $0^{\mathrm{m}}, 170$ x $0^{\mathrm{m}}, 099 ”$. El primer número de la revista se publicó el 31-1- de 1838. 
taban nobles y terratenientes, con especial intervención del banquero catalán afincado en la capital Gaspar Remisa (socio n. ${ }^{\circ} 118$ del Liceo).

El escritor, con toda la experiencia que había adquirido en su exilio en París y Londres, renovará el periodismo nacional, fundando el gran diario del liberalismo moderado y reformador, El Español ${ }^{29}$, verdadero puntal propagandístico de los ideales monárquico-constitucionales.

Recordando de nuevo las palabras de Antonio Ferrer del Río, comprobamos cómo el ambiente de este establecimiento tipográfico reúne a los mismos personajes que vamos a encontrarnos a lo largo de este artículo: Francisco de Paula Mellado y los fundadores del Liceo Artístico y Literario.

[...] omisión censurable fuera aludir a la prensa, y no hacer mención de un periódico de grande importancia. Su título era El Español y su fundador y propietario se llamaba don Andrés Borrego. [...] Cordial acogida halló la juventud anhelosa dentro de aquella redacción magníficamente montada en la calle de las Rejas, donde la reina Cristina tuvo con mucha posterioridad su palacio.

A la sección taquigráfica de El Español hay que dedicar aquí un entrañable recuerdo por razones muy especiales y alguna positiva. Jefe de tal sección era don Ángel Ramón Martí, hijo de Francisco de Paula, feliz inventor de la taquigrafía española [...].

Bajo la dirección de Martí figuraron como taquígrafos de El Español, entre los aún vivos, don Eugenio Moreno López, don Antonio María Segovia, don Francisco de Paula Mellado, nombres todos bien conocidos desde entonces; entre los difuntos el inolvidable don Juan Bautista Delgado, el sentencioso don Luis Segovia, el fecundo proyectista don José Fernández de la Vega. Este último concibió el pensamiento de reunir en su casa una vez por semana a varios amigos para cultivar las letras y las artes; al golpe halló séquito bastante, y apenas tuvo que poner en juego su inquebrantable perseverancia. No otro fue el principio del Liceo Artístico y Literario [... $]^{30}$

Borrego, que aunque de ideas políticas conservadoras, siempre hizo gala de un inusual tono democrático, dispuso en su redacción de una joven generación de periodistas españoles de un amplio espectro ideológico, entre los que destacamos a José Zorrilla, Mariano José de Larra, Francisco Navarro Villoslada (carlista), Luis González Bravo, Antonio Ríos Rosas (socio del Liceo n. ${ }^{\circ}$ 723), Bernardino Núñez de Arenas, Santos López Pelegrín, José García de Villalta $^{31}$, Juan Donoso Cortés (socio del Liceo desde 1838), Espronceda,... y como hemos visto, el propio Mellado, otorgándole al diario un carácter independiente ${ }^{32}$. Poco después se encargará del proyecto del mencionado Correo Nacional (1838-1841) ${ }^{33}$.

${ }^{29}$ Hartzenbusch, José Eugenio, Op. Cit.: "Pr. Con 4 páginas de $0^{\mathrm{m}} .423$ x $0^{\mathrm{m}} .275$, el 1 . $^{\text {o }}$ de Nov. de 1835 , continuando con varias alternativas en su tamaño hasta el 31 de Diciembre de 1837 que tenía $0^{\mathrm{m}}, 425$ x $0^{\mathrm{m}}$, 274 y es el último número que he visto de la época. Dirigió ese periódico el Sr. Andrés Borrego."

${ }^{30}$ Ferrer del Río, Antonio, Op. Cit. pp. 616 y 617.

31 Andrés Borrego abandona el periódico y a partir de 2-6-1837 García de Villalta lleva la dirección y González Bravo realiza las funciones de redactor jefe.

32 Dimitirá como director (15-8-1836) después de la revolución de la Granja. Lo dirigirán los progresistas Juan José Carrasco y Manuel de Lis, sucedidos al poco tiempo por Collantes y este por Villoslada, finalizando su 1. ${ }^{\text {a época }}$ (31-12-1837).

${ }^{33}$ Hartzenbusch, Eugenio, Op. Cit. "Pr. El 16 de Febrero de 1838 con 4 páginas de $0^{\mathrm{m}}, 445$ x 0"m 281. Después tuvo algunas variaciones en su tamaño. Cesó el 15 de junio de 1842 con $0^{\mathrm{m}}, 405$ x $0,{ }^{\mathrm{m}} 274$ ". 
Entre otras de las publicaciones de la época que contribuyeron al rápido y determinante desarrollo del Liceo contamos con revistas ilustradas como el Semanario Pintoresco Español (3-4-1836/20-12-1857) de Mesonero Romanos (socio n. ${ }^{\circ}$ 164), el No me Olvides (7-5-1837/ 11-2-1838) de Jacinto Salas y Quiroga (socio n. ${ }^{\circ}$ 172), El Piloto (1-3-1839/ 133-1840), El Corresponsal (1-6-1839/ 14-5-1844), dirigido por Buenaventura Carlos Aribau (socio n. ${ }^{\circ}$ 641), La Legalidad (8-8-1839/ 23-3-1840) dirigido por Luis González Bravo o El Entreacto (31-3-1839/ 28-3-1841).

Mellado, desde sus inicios como editor, también daba buena cuenta de las actividades del Liceo en las publicaciones que imprimía o dirigía. En el siguiente esquema presentamos aquellas que cronológicamente incluyen el periodo de inicio del Liceo (1837) y el del inicio en la publicación del Museo de las Familias (1843-1870), la revista más representativa de su establecimiento tipográfico, y en el que estamos poniendo el foco. Como se puede comprobar, la mayoría de sus directores pertenecían al Liceo, otra prueba más de la fluida relación entre los componentes de la asociación y el editor:

Tabla 3. Publicaciones periódicas de la editorial de Mellado (1837-1843)

\begin{tabular}{|c|c|c|c|c|}
\hline $\begin{array}{c}\text { La Estafeta } \\
(15-11-1835 / \\
8-5-1838)\end{array}$ & $\begin{array}{c}\text { La Mariposa } \\
(10-4-1838 / \\
25-6-1840)\end{array}$ & $\begin{array}{c}\text { Fray Gerundio } \\
\begin{array}{c}(1-7-1838 / \\
17-8-1841)\end{array}\end{array}$ & $\begin{array}{l}\text { Cervantes y } \\
\text { Velázquez } \\
(5-8-1839 / \\
30-10-1839)\end{array}$ & $\begin{array}{c}\text { La Voz de } \\
\text { Septiembre } \\
(1840)\end{array}$ \\
\hline $\begin{array}{l}\text { Primer diario solo } \\
\text { de noticias. } \\
\text { Editor responsable } \\
\text { Mellado }\end{array}$ & $\begin{array}{l}\text { Literatura y modas. } \\
\text { Dir.: Romero Larrañaga. } \\
\text { Impr. Mellado y } \\
\text { después Omaña }\end{array}$ & $\begin{array}{l}\text { Periódico satírico } \\
\text { Dir. Modesto } \\
\text { Lafuente. } \\
\text { Impr. Mellado }\end{array}$ & $\begin{array}{l}\text { Literario y artístico. } \\
\text { Impr. Mellado y } \\
\text { después Omaña }\end{array}$ & $\begin{array}{l}\text { Revista política. } \\
\text { Impr. Mellado }\end{array}$ \\
\hline $\begin{array}{l}\text { El Mercurio } \\
\text { Español } \\
(1840)\end{array}$ & $\begin{array}{l}\text { El Labriego } \\
(22-2-1849 / \\
30-12-1840)\end{array}$ & $\begin{array}{c}\text { El Ramillete } \\
(15-3-1840 / \\
18-6-1840)\end{array}$ & $\begin{array}{l}\text { El Cotidiano } \\
(1-10-1840 / \\
31-12-1840)\end{array}$ & $\begin{array}{c}\text { El Amigo de la } \\
\text { Niñez } \\
(1-1-1841 / \\
26-3-1842)\end{array}$ \\
\hline $\begin{array}{l}\text { Periódico } \\
\text { administrativo, } \\
\text { científico y literario. } \\
\text { Impr. Mellado }\end{array}$ & $\begin{array}{l}\text { Periódico político. } \\
\text { Dir. García de Villalta } \\
\text { Impr. Mellado y la de } \\
\text { El Labriego }\end{array}$ & $\begin{array}{l}\text { Periódico ilustrado } \\
\text { de recreo. } \\
\text { Impr. Mellado }\end{array}$ & $\begin{array}{l}\text { Diario de anuncios, } \\
\text { instrucción y } \\
\text { recreo. } \\
\text { Impr. Mellado }\end{array}$ & $\begin{array}{l}\text { Ilustrado. } \\
\text { Impr. Mellado } \\
\text { y en } \\
\text { C/ del Barco, } 26\end{array}$ \\
\hline $\begin{array}{c}\text { El Iris } \\
\text { (febr./. nov. 1841) }\end{array}$ & $\begin{array}{c}\text { Revista de España } \\
\text { y del Extranjero } \\
(1-1-1842 / 1844)\end{array}$ & $\begin{array}{c}\text { La Iberia } \\
\text { Musical } \\
5(2-1-1842 / \\
15-2-1842)\end{array}$ & $\begin{array}{l}\text { El Avisador } \\
(1-6-1842 / \\
15-2-1844)\end{array}$ & $\begin{array}{c}\text { El Mentor de la } \\
\text { Infancia } \\
(4-6-1843 / 1845)\end{array}$ \\
\hline $\begin{array}{l}\text { Semanario } \\
\text { ilustrado. } \\
\text { Dir. e Impr. Mellado }\end{array}$ & $\begin{array}{l}\text { Rev. política y Literaria. } \\
\text { Dir. Fermín Gonzalo } \\
\text { Morón. } \\
\text { Impr. Mellado y } \\
\text { después Plazuela de } \\
\text { S. Miguel e } \\
\text { Impr. Del Archivo Militar }\end{array}$ & $\begin{array}{l}\text { Primer } \\
\text { periódico } \\
\text { musical. } \\
\text { Dir. Joaquín } \\
\text { Espín y Guillén. } \\
\text { Impr. Mellado. }\end{array}$ & $\begin{array}{l}\text { Diario de anuncios } \\
\text { y noticias locales. } \\
\text { Impr. Mellado }\end{array}$ & $\begin{array}{l}\text { Semanario. } \\
\text { Dir. Muñoz } \\
\text { Maldonado. } \\
\text { Impr. Mellado } \\
\text { y S. Saunaque }\end{array}$ \\
\hline
\end{tabular}


Así en El Iris, una de las revistas literarias más reputadas del momento ${ }^{34}$, como acabamos de ver publicada en 1841, además de composiciones poéticas leídas o premiadas en las reuniones de la asociación, se incluían avisos para los socios. De este modo se convertía en el medio de comunicación óptimo entre el asociado y la asociación, por lo que el editor Mellado cumplía un doble objetivo: por motivos colaterales afianzar su revista y además poner en valor las actividades del Liceo.

La visita de la reina M. ${ }^{a}$ Cristina al Liceo Artístico Literario (30-1-1838) ${ }^{35}$, supone un canto del cisne para el ego de Fernández Vega, quien tiene el honor de recibirla con estas palabras: "[...] será un monumento de eterno recuerdo que testifique a las generaciones futuras que, reinando Isabel II y gobernando su augusta madre, las Letras y las Artes florecieron en España en medio de los estragos de la guerra civil". ${ }^{36}$

Tras esos primeros momentos de fundación de la sociedad, pronto el manifiesto descontento de los socios por el excesivo protagonismo del Presidente y Conservador obliga a buscarle una salida honrosa ${ }^{37}$ a finales de marzo de 1838, apareciendo en la revista de la asociación el siguiente comunicado:

A petición de su Conservador, José Fernández Vega, el cual en la Junta General celebrada el 24 del mismo fue electo presidente después que el Liceo determinó, que en muestra de su aprecio se le declarase Fundador del mismo, haciendo que este título constase en los archivos del Establecimiento, y que se colocase su retrato en el salón de sesiones, reservándole un puesto de honorífica preferencia al lado del Presidente, siendo vocal perpetuo de las juntas Gubernativa y Económica.

D. José Fernández Vega, después de manifestar que el honor que el Liceo le dispensa era para él la mayor recompensa que pudieran alcanzar sus esfuerzos en beneficio del Instituto; suplicó se le admitiese benévolamente la dimisión del cargo que se le confiaba, por creerle superior a sus fuerzas.

En consecuencia el Liceo procedió al nombramiento del nuevo presidente, y fue elegido el Excmo. Sr. Don Gaspar Remisa [...]. ${ }^{38}$

${ }^{34}$ Entre sus colaboradores contaba con gran parte del equipo de El Artista, quienes, como no podía ser de otra manera, participan como socios en el Liceo.

35 Diferentes publicaciones recogieron la fiesta del palacio de Villahermosa. Entre ellas destacamos El Panorama (T-1, n. ${ }^{\circ}$ 2, 10-1-1839), dirigida por Villabrille, con colaboradores como Muñoz Maldonado, Campoamor o Amador de los Ríos; el No me Olvides (n. ${ }^{\circ} 40,4-2-1838$, p. 7, incluyendo también en diferentes números publicidad de la revista del Liceo (24 y 31 de dic. de 1838 o 28-1-1839) de Salas y Quiroga, todos ellos colaboradores habituales del Museo de las Familias de Mellado, y el Semanario Pintoresco Español (6-1-1839, pp. 7-8), cuyos colaboradores tras el abandono de Mesonero de la dirección participarán preferentemente en el Museo de Mellado o en El Laberinto de Antonio Flores.

36 Pérez de Guzmán, Juan, Op. Cit. p. 203.

37 Su nombre desaparece de los catálogos de 1841-1842, los únicos que fueron editados por el propio Liceo. Revista del Liceo Artístico Literario, Madrid, impr. de la Compañía Tipográfica, 22-3-1838. Tras abandonar la presidencia del Liceo es nombrado Jefe de primera Instancia de un juzgado de Alcalá de Henares y continúa con importantes negocios asociándose a amigos como Joaquín Fagoaga y Pablo Cabrero, destacado miembro del Liceo (miembro n. $\left.{ }^{\circ} 46\right)$. Con ellos constituye la Compañía para el lavado mecánico de ropas al vapor. Cabrero (teniente alcalde de Madrid, 1836), coronel militar aragonés, se casó en 1818 con Josefa Martínez (hija del afamado platero Antonio Martínez), propietarios de la fábrica de platerías Martínez. Su presencia y la de sus hijas, Julia y Paulina, era habitual en el Liceo.

38 Revista del Liceo Artístico Literario, Madrid, Impr. de la Compañía Tipográfica, (22-3-1838). 
Quien había sido uno de los principales inversores de la Compañía Tipográfica, el banquero Gaspar Remisa, será nombrado nuevo presidente. Entre los pocos cargos que se modifican rápidamente se encuentra el del Bibliotecario Pedro González Mate (socio n. ${ }^{\circ}$ 362), quien es sustituido por una persona de la total confianza de la nueva Junta, Juan Eugenio Hartzenbusch (socio n. ${ }^{\circ}$ 160). En la BNE se conserva una carta manuscrita que envió Francisco de Paula Mellado (socio n. ${ }^{\circ}$ 90) como Secretario General del Liceo a Hartzenbusch ${ }^{39}$ informándole de su nombramiento como nuevo Bibliotecario del Liceo. Este documento certifica la importancia del joven editor en la asociación, quien desempeñaba en aquel momento un discreto papel en la dirección, apoyando principalmente el arte y la cultura, sin olvidar su conocido soporte a la causa cristina en contra del frente carlista ${ }^{40}$.

Pero la dirección no fue el único aspecto que cambió en el Liceo: atrás iban a quedar sus vínculos con los románticos, arrinconados en este nuevo rumbo, por el ideal del eclecticismo más castizo:

[...] el LICEO no será, pues, dogmatizador ni apóstol de ninguna secta literaria, si quier apareciese revestida esta de las más altas pretensiones. Tampoco entrará en liza contra el más humilde de los géneros; porque si el individuo es bueno, habría poca generosidad y justicia en condenarle a causa solo de su alcurnia. No será el LICEO, por ejemplo, clásico y romántico en el sentido común de estas palabras; pero no combatirá tampoco el clasicismo, porque respeta las obras de SOLÍS, de RACINE, del TASSO y de MILTON; ni al Romanticismo, porque no desprecia CALDERÓN, SHAKESPEARE, a BYRON, ni al ARIOSTO.

Independientes, pues, de toda mira y controversia mezquina, tendrán por objeto los trabajos del LICEO rectificar el buen gusto de la juventud, ya sea con las reglas, ya con el ejemplo que de ellas podrán dar escogidas composiciones; señalarle los escollos de que la carrera artística se halla sembrada, previniendo así los extravíos a que las vanas teorías y los sistemas intolerantes convidan; y encaminándola a la luz de la verdad y del fundado saber artístico, hacia aquella perfectibilidad ideal que no desdeñó PLATÓN, y que debe ser siempre la brújula del verdadero artista $[\ldots]{ }^{41}$

Sin duda, el cambio de ubicación definitivo al palacio de Villahermosa, ya con Gaspar Remisa en la dirección ${ }^{42}$, también supuso un antes y un después en el desarrollo de las actividades de la asociación.

39 Mellado, Francisco de Paula (22-12-1840): "Carta de Francisco de Paula Mellado, secretario general del Liceo Artístico y Literario, a Juan Eugenio Hartzenbusch informándole de su nombramiento como bibliotecario y archivero del mismo", Madrid; forma parte de los Papeles de Juan Eugenio Hartzenbusch, serie Correspondencia profesional y académica en la BNE.

${ }^{40}$ Recordamos que en este periodo de formación y florecimiento del Liceo Artístico y Literario se desarrolla la $1^{a}$ guerra carlista (1833-1840), centrando la vida política y social de los españoles.

41 "La nueva redacción del Liceo al público" (1838): Revista del Liceo Artístico y Literario, Madrid, Compañía Tipográfica, p. 5. Otras medidas recogidas en este texto, como las de llevar la publicación a la casa de los suscriptores (p.7: "[...] Para principiar estas mejoras ha resuelto la junta Gubernativa, que desde el presente número inclusive igual el precio del LICEO, costando solo 10 rs. tanto en Madrid como en provincias (franco porte), llevándolo a casa de los señores suscriptores [...]"), apuntan directamente a la implicación en la sombra del editor Mellado, quien introdujo este novedoso método en nuestro país como un importante incentivo para incrementar las ventas.

${ }^{42}$ El banquero barcelonés dirige el Liceo hasta su fallecimiento. Sus actuaciones incluyen una importante e imprescindible labor de mecenazgo. 
Así lo explicita Antonio Ferrer del Río: “[...] bastante de su carácter primitivo perdió el Liceo Artístico Literario desde su traslación a la casa del Duque de Villahermosa [...]”43.

Esta crisis de identidad se agudiza en 1843 tras la caída como regente del general Espartero, dividiendo los apoyos progresistas y el peso de estos en la asociación. Paulatinamente, las sesiones de competencia se contemplaban como tediosos ejercicios obligatorios, no académicos sino lúdicos. Las relaciones sociales primaban ante las culturales y muchos de los intelectuales que la fundaron dejaron de asistir. A estas circunstancias se unió el prematuro fallecimiento de José de Espronceda (25-5-1842), líder natural de los intelectuales más progresistas. Uno de sus colegas más incondicionales, Enrique Gil, califica con crítica nostalgia la situación del Liceo a finales de 1843. En la institución organizaron una fiesta en honor a la reina (23-12-1843) para celebrar su mayoría de edad, a la que acudirán la joven monarca, su hermana y su séquito; entre ellos se encontraban su tío, el infante D. Francisco, y su esposa. En ella Gertrudis Gómez Avellaneda lee y dedica una oda a la reina que la conmueve. Gil y Carrasco lamenta que el Liceo de esa época no sea comparable al de los inicios y les desea que recuperen su esencia original:

[...] Esta corporación que en tiempos más felices para ella, sino más lúcidos que los presentes, celebró con una agradable y linda fiesta en el jardín de las Delicias el memorable convenio de Vergara, [...]. Deber nuestro es sin embargo, y ojalá todos fuesen tan agradables de cumplir, consignar un recuerdo del interés con que la soberana protección mira un establecimiento que por no haberse apartado algún tanto de su primitivo carácter, deja de estar animado del genio de las artes, ni de ser ya que no su templo, por lo menos su palacio [...]. ${ }^{44}$

Disponemos de un testimonio similar gracias a Basilio Sebastián Castellanos, quien en el elocuente título de la recopilación de sus poesías pone de manifiesto los males evidentes de los que adolecía la asociación:

Obras de su juventud reproducidas después para llenar su turno en el Instituto Español y el Liceo Literario, en cuyas amenas sesiones era preciso leer composiciones ligeras que divirtiesen a las señoras y no disertaciones académicas y recordarlas también para pagar la contribución de los álbumes, impuesto sino metálico, no menos vigoroso que el sistema tributario, porque si aquel pone en conflicto el bolsillo, este pesa sobre el espíritu del pobre contribuyente [...]..$^{45}$

Años más tarde, en 1848, Pascual Madoz incide nuevamente en la pérdida cualitativa de valor artístico de las reuniones, aspecto que, tras esos intensos momentos de génesis, en más ocasiones será puesto en tela de juicio:

[...] Los artistas fundadores fueron Villamil, Esquivel, Gutiérrez, Gómez, Avrial. De tres años a esta parte, por diferentes causas había decaído mucho, perdiendo el carácter artístico, base de su existencia, pero habiendo intentado regenerarle la junta gubernativa, ha tenido la fortuna de conseguirlo, volviendo a la sociedad los artistas y literatos que se habían alejado de ella, y en la actualidad goza de una existencia tan próspera como en sus mejores días [... ${ }^{46}$

${ }^{43}$ Ferrer del Río, Antonio. Op. Cit. p. 618.

${ }^{44}$ Gil y Carrasco, Enrique, (1-1-1844): El Laberinto, "Revista de la Quincena", Madrid.

${ }^{45}$ Castellanos de Losada, Basilio Sebastián (1848): Álbum de mi familia y de mis amigos: poesías de Basilio Sebastián Castellanos de Losada, Madrid, Imprenta de la viuda de Sánchez e hijos.

${ }^{46}$ Madoz, Pascual (1848): Diccionario geográfico-histórico-estadístico de España y sus posesiones de ultramar, Madrid, Mellado, p. 318. 


\section{Con amarga nostalgia también es descrito por el Barón de Parla-Verdades en 1849:}

[...] Y sin embargo, no hace aún mucho tiempo que resonaba en toda la península el nombre y la celebridad del Liceo Artístico y Literario de la corte. Allí concurría la sociedad más escogida y elegante, las damas más distinguidas por su gracia y hermosura, los hombres de posición más elevada, los grandes de España, los ministros, los banqueros, los altos funcionarios públicos, en una palabra, todas las notabilidades madrileñas; S.M. misma se dignaba honrar con mucha frecuencia los magníficos solares de Villahermosa. Allí se alzaba el eco tierno y melancólico de Enrique Gil, la voz amarga y desgarrada de Larra, el acento enérgico y apasionado de Espronceda, la canción sonora y fantástica de Zorrilla. Allí encantaba y conmovía a los espectadores la musa de Vega, de García Gutiérrez, de Rubí, de Bretón de los Herreros. Allí, en fin, rivalizaban dignamente los pinceles de Rivera, Esquivel, Villamil y Madrazo. ¡Oh! Aquello sí que podía llamarse un Liceo, un círculo literario y artístico, un templo levantado al genio coronado con el laurel de la gloria. Pero ese templo no existe; Enrique Gil, Larra y Espronceda murieron en la flor de sus días: los demás poetas y artistas han arrojado sus liras y sus pinceles, o se han retirado al fondeo de sus gabinetes de estudio, divididos y diseminados por el tiempo y la fortuna. La juventud nueva apenas brota dignos herederos de sus lauros, y los LICEOS de Madrid han venido a reducirse a algunas tertulias donde, como todo tributo a las artes, se baila la polka-mazurka y se hacen comedias caseras $[\ldots] \cdot{ }^{47}$

El propio Mesonero, también en su momento bibliotecario del Liceo, analiza cómo con el tiempo la asociación se convirtió en un trampolín para políticos y diplomáticos y abandonó paulatinamente su pátina cultural y literaria:

[...] Pero, pasados aquellos momentos (o sean años) de ardiente fe y sed entusiasta de gloria, la tendencia del siglo se inclinó a materializar los goces y a utilizar prosaicamente las inteligencias; por eso los institutos de esta clase fueron amenguando; por eso fueron desamparándolos sus expansivos y sobradamente generosos ingenios, corriendo a las redacciones de los periódicos políticos, a la tribuna o a la plaza pública, a conquistar, no aquellos modestos y espontáneos laureles, sino los atributos del poder y los dones de la fortuna. De los hombres que arriba cité como sostenedores de la tribuna del Liceo, según se presentaron en mi memoria, casi todos ellos figuraron después como ministros, embajadores, consejeros, senadores, diputados y publicistas, alternando en diversos bandos y épocas, según la marcha de los sucesos [...]. ${ }^{48}$

Quizá estas mismas circunstancias explicarían que el núcleo fundador, del que formaba parte Mellado, se alejara de la asociación como también lo hizo el propio Mesonero. Lo que podemos apuntar como cierto es que en esos primeros años los fundadores y participantes del Liceo funcionaron como un todo unitario, ayudándose unos a otros en su desarrollo profesional y cultural. Sin duda un estudio profundo sobre la relación entre Francisco de Paula Mellado y el Liceo Artístico y Literario, aquí tan solo apuntada, proporcionará interesantes y reveladores datos sobre el mundo cultural y político de la época.

${ }^{4}$ Parla-Verdades, Barón de (1987): Madrid al daguerrotipo, Madrid, Imprenta de L. García. 1849. Edición facsímil Impr. Comunidad de Madrid, p. 321. El Barón parece disponer de la ficción al servicio de la verdad. Como ya hemos recordado, tristemente Larra se suicidó el 13-2-1837, luego no hubo posibilidad de que asistiese a las reuniones del Liceo.

${ }^{48}$ Romanos Mesonero, Ramón de, (22-10-1879): "Memorias de un setentón”, La Ilustración Española y Americana, Madrid, Abelardo de Carlos, p. 250. 
El segundo plano omnipresente del editor va más allá de los momentos más gloriosos de la asociación; de manera inversamente proporcional, mientras la sociedad le acerca paulatinamente a los círculos más conservadores, con personajes como el conde de Fabraquer, quien se manifestará como una presencia constate en su aventura periodística y editorial, se alejará de sus amigos y colegas más progresistas, anglófilos y partidarios del ya exiliado Espartero.

Estas circunstancias quedan patentes en el Museo de las Familias (1843-1870) ${ }^{49}$ en la que comprobamos cómo la lista de colaboradores literarios, periodistas, grabadores y dibujantes de la primera serie y la de los socios del Liceo presenta notables coincidencias: Calixto Ortega (socio n. ${ }^{\circ}$ 215), Vicente Castelló (socio n. ${ }^{\circ}$ 192), José M. ${ }^{a}$ Avrial (socio n. ${ }^{\circ}$ 186), Eusebio Zarza (socio n. ${ }^{\circ}$ 465), Bretón de los Herreros, Hartzenbusch, Muñoz Maldonado (socio n. ${ }^{\circ}$ 753), Modesto Lafuente, el duque de Rivas (socio n. ${ }^{\circ}$ 217), Gregorio Romero Larrañaga (socio n. ${ }^{\circ}$ 140), Paulina Cabrero (socia n. ${ }^{\circ} 138$ ), Campoamor (socio n. ${ }^{\circ}$ 148), José Amador de los Ríos (socio n. ${ }^{\circ}$ 919?), Gertrudis Gómez de Avellaneda (socia n. ${ }^{\circ}$ 1081), Augusto Ferrán (socio n. ${ }^{\circ}$ 197), Antonio Ferrer del Río (socio n. . 1236), Salvador Bermúdez de Castro (socio

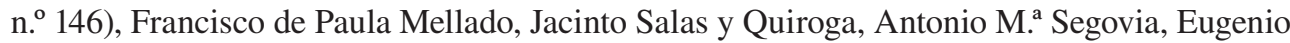
de Ochoa (consta como socio desde 1838), Mesonero Romanos (socio n. ${ }^{\text { }} 164$ ), Ventura de la Vega o José de la Revilla (consta desde 1838).

En algunas ocasiones, en esos primeros tomos de la revista, el editor Mellado incluye entre sus páginas composiciones poéticas relacionadas directamente con el Liceo de Madrid o con el de Valladolid.

Tabla 4. Composiciones poéticas relacionadas con el Liceo publicadas en el Museo de las Familias

\begin{tabular}{|l|l|l|}
\hline \multicolumn{1}{|c|}{ AUTOR } & \multicolumn{1}{|c|}{ TÍTULO - DESCRIPCIÓN } & \multicolumn{1}{|c|}{ LOCALIZACIÓN } \\
\hline V. Sainz Pardo & $\begin{array}{l}\text { "Romance" - En nota: “Esta composición ha sido leída con } \\
\text { aplauso en el Liceo de Valladolid y se nos ha remitido por el } \\
\text { autor para su inserción en nuestro periódico" }\end{array}$ & Tomo I; p. 219 \\
\hline El Estudiante & $\begin{array}{l}\text { "Valor del tiempo o una cita desgraciada" - Composición leída } \\
\text { en el Liceo }\end{array}$ & Tomo II; p. 247 \\
\hline Gregorio Romero Larrañaga & $\begin{array}{l}\text { "Oda a la muerte de Felipe II" - Para el concurso del Liceo en } \\
1843\end{array}$ & Tomo IV; p. 90; \\
\hline
\end{tabular}

Sorprende gratamente cómo las actividades del Liceo entran a formar parte de los contenidos narrativos de la revista. Así, Luis Villanueva en un pormenorizado estudio biográfico refresca la memoria de los lectores, rememorando el triste episodio de la dolencia herpética y posterior depresión del pintor Antonio M. ${ }^{a}$ Esquivel $^{50}$ y la incondicional ayuda que le prestó

${ }^{49}$ En La Crónica (6-10-1844/28-9-1845), semanario publicado por Mellado, también mencionan las sesiones del Liceo en esta etapa de menor auge.

${ }^{50}$ En el Liceo se realiza una sesión de beneficio a su favor (8-4-1840) cuando Francisco de Paula Mellado era Secretario General de la misma. En ella tomaron parte activa todas las secciones de la asociación alcanzando una recaudación de 26.725 rs. Tras un primer obsequio, "La caída de Luzbel" (1841), el pintor inmortalizó para siempre la sociedad y a sus amigos y colegas, entre ellos Fernández de la Vega, en "Los poetas Contemporáneos o Lectura de José Zorrilla en el estudio del pintor" (1846). 
la asociación. El artículo se publica cuatro años después de los actos que se realizaron en el Liceo para conseguir fondos que ayudasen al artista en su enfermedad:

[...] Fue uno de los fundadores del Liceo de Madrid. [...] El año de 1840, cuando ya se hallaba como hemos dicho ocupando un lugar distinguido entre los buenos artistas de la corte, un humor herpético que le cayó a los ojos, hizo que todos sus amigos y admiradores llorásemos su pérdida [...]. Los liceos, los teatros, las corporaciones todas, acudieron con beneficios a su favor [...].

Recobrada esta, fue su primer cuidado corresponder a las muestras de aprecio y generosidad con que el liceo de Madrid le había socorrido durante su desgracia y con este motivo regaló al liceo el famoso cuadro de "La caída de Luzbel" [...]. ${ }^{51}$

Es el cuñado del editor, Juan Leguey, quien presentará el palacio de Villahermosa como la ubicación perfecta para un relato fantástico en una encantadora y misteriosa velada del baile de máscaras de carnaval. La manera más idónea para conocer de primera mano el predicamento del que disponían estos eventos, considerados como imprescindibles para la sociedad madrileña isabelina, en esta ocasión conllevaba la descripción de una escena de aglomeración a las puertas del Liceo de los carruajes más lujosos y exquisitos, muestra indudablemente del alto nivel adquisitivo de sus importantes propietarios:

[...] Tal era pues la agitación y el movimiento que se notaba [...]. Mil carruajes de diferentes hechuras, celeridad y aún de opuestas edades, cruzaban velozmente; parecía imposible que el pueblo de Madrid cerrase en su seno tanta máquina ambulante; aquí se veía un soberbio landó perfectamente encristalado, tirado por un par de famosas yeguas cubiertas hasta las orejas de encerado y que guiaban desde el cómodo y elevado pestante dos vigorosos y fornidos descendientes del valiente D. Pelayo, herméticamente envueltos en sus carriques blancos de 5 cuellos, con sombrero galoneado de oro, su corbata también blanca, y colorados y orgullosos porque a juzgar por las apariencias, eran los timoneros de aquel bajel que debía pertenecer a algún cortesano o diplomático de la más elevada alcurnia; en dirección contraria se veía pasar a su lado al perezoso y sosegado coche de alquiler, o sea dicho "simón", que así se parece al anterior como un vapor a una barca de remos; que arrastraban con sobrada lentitud dos escuálidos cuadrúpedos [...]; más allá se veía trotar con más prisa que a un agente de negocios, a la carretela de mulas con campanillas y mayoral de tralla en ristre y marselle cordobés; al rápido bombé del médico o del agente de bolsa, al problema de los carruajes, al disfrazado y elegante tílburi, aunque no tan fresco y escotado como en el estío, sino calada en su capucha: a la tartana, de origen desconocido e infernal invención, a los ómnibus, especie de cetáceos terrestres, y sobre todos no faltaba el calesío español, mahometano o del tiempo de Adán, que atrevido y alegre surcaba por las calles tan rápido cual si le esperara un chulo de los que han de lidiar los toros en una tarde de corrida.

Todos estos carruajes iban llenos de gentes, que acudían a los bailes de máscaras. Era martes de carnaval $[\ldots]^{52}$

Este revelador texto pone en evidencia una vez más cómo los eventos sociales desplazaron por completo a los culturales en el Liceo Artístico y Literario, sombra desdibujada de lo que en origen había sido. De igual manera se disolvió la mezcla de clases sociales de las primeras reuniones y se convirtió en un espacio más para disfrute de la élite madrileña.

51 Villanueva, Luis (1844): “Don Antonio María Esquivel”, Museo de las Familias, Madrid, Mellado, pp. 90-93.

${ }^{52}$ Leguey, Juan (1844): "Una noche en Villa-Hermosa”, Museo de las Familias, Madrid, Mellado, pp. 41-44. Con un grabado de Castelló y Zarza. 
El editor Mellado tampoco se olvidó de poner al servicio del Liceo su establecimiento tipográfico y se encargará tanto de la publicación de catálogos y boletines, como de obras de sus socios, como lo certifican los siguientes ejemplos: Liceo artístico y literario. Catálogo de las obras de pintura, escultura y arquitectura presentadas a exposición en Junio de 1846; Poesías de Ramón de Campoamor. Publicadas por el Liceo Artístico y Literario, Impr. de Mellado, 1840; "A Sevilla" de Ventura de la Vega, obra premiada por mano de S.M. en la sesión que celebró el Liceo Artístico y Literario de Madrid el 13 de septiembre de $1843 . .$. , la Memoria de la Junta delegada del Liceo Artístico y Literario de Madrid: leída en la Junta general (años 1845, 1846, 1847,...), Boletín del Liceo, Madrid, Liceo Artístico y Literario, Establecimiento Tipográfico de F. de P. Mellado (comenzó en 1845; cesó en 1846) o el Catálogo de los socios del Liceo Artístico y Literario de Madrid.

Estas publicaciones muestran cómo Mellado permanece atento a la asociación hasta el final de la década de los cuarenta, aunque no tenemos constancia de que este apoyo se mantuviese con la nueva dirección del duque de Riánsares (1847-1851).

El panorama en la dirección del Liceo Artístico Literario nos ayuda a sacar conclusiones: el banquero Gaspar Remisa (presidente de 1838-1841 y de 1843-1846), el duque de Riánsares, el Marqués de Salamanca (socio n. ${ }^{\circ} 852$, presidente provisional en 1846), el financiero Nazario Carriquiri (miembro de la sección de Adictos internos, Depositario en 1841, socio n. $\left.{ }^{\circ} 678\right), \ldots$ son una pequeña muestra de los individuos que costaban en su dirección y las directrices que podrían generar.

Para Francisco de Paula Mellado y su círculo la permanencia en el ámbito cercano al Liceo Artístico y Literario implicaba el tener al alcance de su mano una importante red de relaciones sociales. Esta circunstancia favoreció que asimilaran el hecho de que, inevitable, los originarios objetivos culturales de la misma iban a ser flor de un día.

Intensos, fructíferos, románticos, los primeros años del Liceo dieron paso a la evolución de sus socios y a los cambios que hemos mencionado.

Al igual que la sociedad isabelina, en continua evolución y crecimiento, Mellado y su participación en el Liceo cambiaron siguiendo caminos paralelos, manteniendo su apoyo a la reina madre M. ${ }^{\text {a }}$ Cristina pero buscado ahora su identidad en un eclecticismo más conservador que su primigenio progresismo romántico. 
